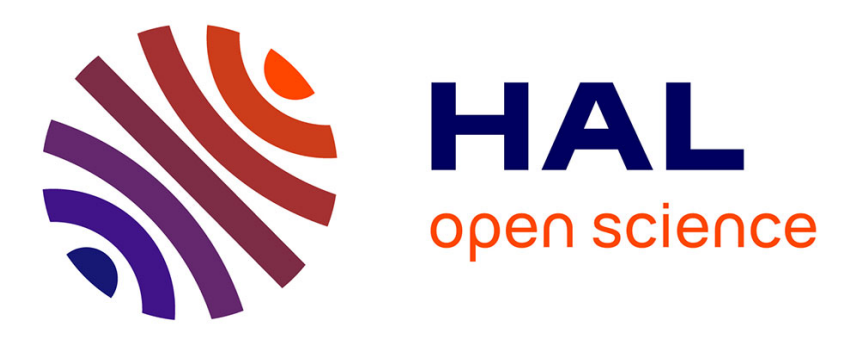

\title{
Adverse effects to suckling mice following indirect exposure to a pesticide mixture and ameliorative effect of $\alpha$-tocopherol coadministration
}

Sameeh Mansour, Mohamed Abdel Mageed, Khaled Mohamed, Marwa Gad, Laurence Gamet-Payrastre

\section{To cite this version:}

Sameeh Mansour, Mohamed Abdel Mageed, Khaled Mohamed, Marwa Gad, Laurence GametPayrastre. Adverse effects to suckling mice following indirect exposure to a pesticide mixture and ameliorative effect of $\alpha$-tocopherol coadministration. Journal of Basic and Clinical Health Sciences, 2017, 1 (3), pp.71-78. 10.5152/jbachs.2017.227 . hal-02624292

\section{HAL Id: hal-02624292 \\ https://hal.inrae.fr/hal-02624292}

Submitted on 26 May 2020

HAL is a multi-disciplinary open access archive for the deposit and dissemination of scientific research documents, whether they are published or not. The documents may come from teaching and research institutions in France or abroad, or from public or private research centers.
L'archive ouverte pluridisciplinaire HAL, est destinée au dépôt et à la diffusion de documents scientifiques de niveau recherche, publiés ou non, émanant des établissements d'enseignement et de recherche français ou étrangers, des laboratoires publics ou privés. 


\title{
Original Article
}

\section{Adverse Effects to Suckling Mice Following Indirect Exposure to a Pesticide Mixture and Ameliorative Effect of $\alpha$-Tocopherol Coadministration}

\author{
Sameeh Mansour', Mohamed Abdel-Mageed², Khaled Mohamed², Marwa Gad', Laurence Gamet-Payrastre ${ }^{3}$
}

' Department of Pesticide Chemistry đ Toxicology, National Research Centre, Giza, Egypt

2 Department of Plant Protection, Ain Shams University, Cairo, Egypt

3 Joint Research Unit I33I, TOXALIM Research Centre in Food Toxicology, Toulouse, France

Address for Correspondence: Sameeh Mansour E-mail:samansour@hotmail.com

$>$ Received: 18.06.2017; Accepted: 07.08.2017

๑Copyright 2017 by Dokuz Eylül University, Institute of Health Sciences - Available online at www.jbachs.org

Cite this article as: Mansour S, Abdel-Mageed M, Mohamed K, Gad M, Gamet-Payrastre L. Adverse Effects to Suckling Mice Following Indirect Exposure to a Pesticide Mixture and the Ameliorative Effect of $\alpha$-Tocopherol Coadministration. J Basic Clin Health Sci 2017; 3: 71-8.

\begin{abstract}
Purpose: The present study was conducted to evaluate the oxidative damage and biochemical and histopathological alterations in suckling mice whose mothers were exposed to a mixture of three pesticides (atrazine "A," chlorpyrifos " $C_{1}^{\prime \prime}$ and endosulfan " $E$ "; $A C E$ ) with and without vitamin $E$ ( $\alpha$-tocopherol) supplementation

Methods: During gestation, the mouse dams were fed a diet free of chemicals. Just after parturition and up to offspring weaning (ca. 20 days), the mouse dams received one of the following diets: (a) a diet free of ACE, (b) a diet enriched with ACE (at Acceptable

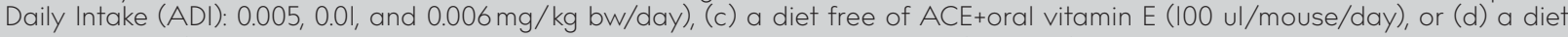
enriched with $A C E+o r a l$ vitamin E. Drinking water was allowed ad libitum up to 42 days. After weaning, blood samples and organs were collected from pups and dams for analyses.

Results: Compared with the control results of dams or their pups, the ACE mixture induced high elevation in AST, ALT, ALP, urea, and MDA and high decline in BuChE, SOD, and CAT. The suckling pups were more affected than the dams with respect to alterations in MDA and BuChE activities, whereas the opposite was observed with respect to SOD activities. Vitamin E supplementation alleviated the oxidative stress exerted by the tested mixture.

Conclusion: The findings of this study explore extension of the adverse effects of the ACE mixture to mouse offspring and the powerful ameliorating effect of vitamin E supplementation.
\end{abstract}

Keywords: Pesticide mixture, lactation exposure, oxidative stress, vitamin E, amelioration

\section{INTRODUCTION}

It is worth to mention that maternal milk is recognized as the most important source of nourishment during infancy. Mothers maybe exposed to lipophilic chemicals from different sources. Such chemicals can be stored and accumulated over time in the body fats. During lactation, they can enter the breast milk by passive transfer from plasma (I). Thus, protecting human milk from chemical contaminants such as pesticides is a subject of major concern to both scientific and regulatory communities. The present study reports the problem of the toxic transfer of pesticides into suckling mice and measures to prevent such cases.

This study is a part of a collaborative research project between Egypt and France; thus, the selection of pesticides was based on currently or previously used compounds in both countries. Three pesticides (atrazine, A; chlorpyrifos, C; and endosulfan, E) in addition to their tertiary combination (ACE) were selected for the collaborative research project. The selected pesticides belong to three different chemical classes, namely, triazines, organophosphates, and organochlorines. These pesticides are still used in several countries for combating agricultural and household pests, and their residues have been found even in countries where in their use is banned (2). Atrazine is still a drinking water contaminant, at very low concentrations, in some countries, including France (3). The concentrations of $\mathrm{E}$ and $\mathrm{C}$ in various foods were found to be around $0.011-0.037 \mathrm{ppm}$ and $0.002-0.1 \mathrm{ppm}$, respectively (4).

According to the protocol of the collaborative research project, we recently investigated the effect of exposure of mouse dams to $A$, $E$, and $C$ during the overall period of gestation and lactation, and the indirect effect of such an exposure on the offspring (5-7). 
We found it to be of interest to elucidate the toxic effects of a mixture comprising the abovementioned pesticides on lactating dams and their suckling mice and to assess the ameliorative effects of vitamin E supplementation.

In fact, about $95 \%$ of studies related to pesticides were conducted on individual chemicals; however, studies on the effect of chemical mixtures on human systems are rare (8). Humans are exposed to a cocktail of chemical compounds through multiple routes of exposure (e.g., ingestion, inhalation, and skin contact), but food remains an important source of exposure. The effects of such exposures on human health are still poorly understood, making risk assessment of chemical mixtures difficult and inaccurate. Major difficulties in this respect are attributed to differences in the exposure levels, periods, and frequencies as well as to the diversity of active substances and adjuvants used in formulating the compounds (3). Certain pesticides in a mixture may interact chemically, mainly because the metabolism of one chemical can affect that of another. Subsequently, mixtures of pesticides can interact additively, synergistically, or antagonistically (9). Potentiation was reported for a mixture of $A, C$, and chlorothalonil $(9,10)$.

It has long been recognized that many pesticides may induce oxidative stress following acute exposure in humans and animals (II). Exposure to not only individual pesticides but also pesticide mixtures can promote oxidative stress by increasing the concentration of reactive oxygen species (ROS) and products of oxidative damage such as lipid peroxides, thereby affecting the activity of antioxidant enzymes (AOEs) (II, I2). Antioxidants such as vitamin E act as biological free-radical scavengers in the cell membranes, thus protecting cells from the damaging effects of the harmful free radicals (I3).

The present study was conducted to evaluate the oxidative damage and biochemical and histopathological alterations in suckling mice whose mothers were exposed to the pesticide mixture ACE and to assess the ameliorative effects of vitamin E supplementation. To the best of our knowledge, there is no data on the ameliorative effects of vitamin E against the tested mixture $A C E$, but there are many publications on such effects against individual pesticides (5-7).

\section{METHODS}

\section{Chemicals and Doses}

High purity PESTANAL ${ }^{\odot}$ Analytical Standards of A (97.4\%), C (99.2\%), and $E(\alpha+\beta=2+1$; $99.9 \%)$ were purchased from Fluka (Riedel-de Haën, France) and added to rodent nuggets at a dose of 25,50 , and $30 \mu \mathrm{g} / \mathrm{kg}$ of food, respectively, as a tertiary mixture (ACE). The rodent nuggets thus prepared were analyzed in Eurofins (Nantes, France), and the actual fortified quantities were around the expected values (i.e., around 25,50, and $30 \mu \mathrm{g} / \mathrm{kg}$ of food, respectively, for A, C, and E). Nuggets prepared for control feed did not show the presence of any pesticide. Based on previous estimates of the average food consumption/mouse, the prepared nuggets allowed the mouse to ingest an equivalent of the acceptable daily intake (ADI) of each pesticide $(0.005,0.01$, and $0.006 \mathrm{mg} / \mathrm{kgbw} /$ day, respectively), as defined for humans during the Joint FAO/WHO Meeting on Pesticide Residues and extrapolated for mice on the basis of their mean body weight $(14,15)$.
$D$ - $L$ $\alpha$-tocopherol acetate was purchased from Fluka (Riedel-de Haën, France). The vitamin was dissolved in corn oil ( $120 \mathrm{mg} / 3 \mathrm{ml})$ and administered by oral gavages twice a week at a dose of 100 ul/mouse according to a study by Kalender et al. (I6).

\section{Animals}

Ten-week-old female and male C57 BL/6 J mice were purchased from Charles River Laboratories (Domaine des Oncins-BP 109, 69592 L'arbresle, Cedex, France). Their mean body weights were $20 \pm 2 \mathrm{~g}$. The animals were acclimatized for 2 weeks before commencement of dosing. Sixteen virgin female mice were distributed into 8 cages. In each cage, one male was placed overnight, and the presence of spermatozoa was checked in the vaginal smear the following morning. This day was connoted as gestation day O (GD 0 ). At that time, pregnant females were individually housed in clean plastic cages in the laboratory animal room $\left(23^{\circ} \mathrm{C} \pm 2^{\circ} \mathrm{C} ; 40 \% \mathrm{RH}\right)$, fed on the prepared diet, and allowed to drink tap water ad libitum. The mouse dams received the tested treatments during lactation period only (20 days), and the day of parturition was considered day 0 of lactation, postnatal day 0 (PND 0). The offspring of each litter were counted and sexed, and each litter was randomly reduced to 6 pups of equal number of sexes to maximize the lactation performance (17). The experimental work on animals was performed in Toxalim Unit, INRA, Toulouse, France and in accordance to its institutional ethical committees in an accredited animal house.

\section{Experimental Design}

During gestation, the mouse dams were fed a diet free of any chemicals. During the lactation period (ca. 20 days), the experimental mouse dams received one of the following treatments: (a) a diet free of $A C E$, control; (b) a diet enriched with $A C E$; (c) a diet free of $A C E+o r a l$ vitamin $E$ ( $\alpha$-tocopherol), I00 $\mu \mathrm{l} /$ mouse; or(d) a diet enriched with ACE+oral vitamin E,I00 $\mu \mathrm{l} /$ mouse. The dose of vitamin $E$ was given twice a week. Pups of the experimental dams were segregated into male and female subgroups, each of 20 animals, representing control, pesticide mixture, vita$\min \mathrm{E}$, and pesticide mixture+vitamin E treatments.

At the end of weaning (ca. 42 days), blood samples were obtained from the facial artery of each animal (dams and pups) and added to non-heparinized centrifuge tubes (Multivette ${ }^{\circledR}$, SARSTED, Germany) for separating sera. Centrifugation was performed on Sigma IKI5 Bioblock Scientific (Subra, France) for $10 \mathrm{~min}$ at $4^{\circ} \mathrm{C}$ and $4000 \mathrm{rpm}(1400 \times \mathrm{g})$. The sera were kept in Eppendorf tubes and stored at $\left(-80^{\circ} \mathrm{C}\right)$. The heart, spleen, liver, kidneys, testes, or ovaries were removed and weighted, and small pieces were placed in 10\% formalin for histopathological analysis. Other pieces of liver were packed in aluminum sheets and placed in nitrogen $\left(-80^{\circ} \mathrm{C}\right)$ for certain biochemical estimations. The fractionated blood samples and specimens of internal organs were shipped frozen in addition to formaldehyde-reserved specimens to the National Research Centre, Cairo, Egypt for biochemical analyses and histopathological studies.

\section{Biochemical Analyses}

Diagnostic kits used in the present study were obtained from Biodiagnostic Co., Dokki, Giza, Egypt. These included aspartate aminotransferase (AST), alanine aminotransferase (ALT), alkaline phosphatase (ALP), butyryl cholinesterase (BuChE), urea, 
malondialdehyde (MDA), superoxide dismutase (SOD), and catalase (CAT). Measurements were performed spectrophotometrically using a Shimadzu ultraviolet-visible recording 240IPC (Japan) in the light of the manufacturer's instructions given in the pamphlets and in accordance with well-known methods. MDA and SOD activities were determined in liver tissues, whereas the other biochemical parameters were measured in sera.

\section{Histology Studies}

Liver, kidneys, ovaries, and testes from the experimental mice were dissected and fixed in 10\% neutral formalin dehydrated in ascending grades of alcohol and embedded in paraffin wax. Paraffin sections (5-mm thick) were stained for routine histological studies using hematoxylin and eosin (H反E). Two slides were prepared for each mouse:each slide contained two sections of each organ. Ten field areas for each section were selected and examined for histopathological changes under a light microscope (400x magnification). The histopathological study was conducted in the Pathology Department, Faculty of Veterinary Medicine, Cairo University, Cairo, Egypt. Tissue injury in the examined organs was scored using different ratings according to a study by Brunt et al. (18).

\section{Statistical Analysis}

The results were expressed as means \pm SE. All the data were statistically analyzed by means of the Statistical Package for Social Sciences version 17.0 (SPSS Inc; Chicago, IL, USA).The results were analyzed using one way analysis of variance followed by Dunnett"s test for comparison between different treatment groups. Statistical significance was set at $p \leq 0.05$.

\section{RESULTS}

\section{Body and Organs Weights}

Table I presents results of body, absolute, and relative organ weights of mouse dams treated with the pesticide mixture during the lactation period and of their pups just after weaning. There were insignificant differences between control and treatment results with respect to the body weights of dams and their pups. The weights of the liver were recorded to be $0.51 \mathrm{~g}$ for female and male pups; this value was significantly higher $(P \leq 0.05)$ than that obtained for the control treatment ( 0.42 and0.42 g). The weight of the dam spleen with the control treatment (0.09 $\mathrm{g}$ ) was very little compared with that with the mixture treatment $(0.29 \mathrm{~g})$, showing a significant difference $(\mathrm{p} \leq 0.0 \mathrm{l})$. The values recorded for absolute weights of the kidney, heart, ovaries, and testes in mouse dams and their pups showed insignificant differences compared with those recorded for the corresponding controls (Table I).

The relative weights of the kidneys, ovaries, and testes with all treatments (Table I) showed insignificant differences when compared with the results of the corresponding controls. The relative weights of the liver from the female and male pups exposed to the mixture were found to be significantly higher $(p \leq 0.05)$ than those of their corresponding controls, whereas the opposite was observed for the weights of the heart. The relative weight of the spleen in the dams treated with the mixture (0.89\%) was significantly higher $(p \leq 0.0 \mathrm{l})$ than that in the control dams $(0.32 \%)$. Conversely, the weight of the spleen in the pups exposed to the mixture was recorded to be $0.37 \%$ and 0.46 , respectively, for female and male animals; these values were statistically $(p \leq 0.0 \mathrm{l})$ lower than the control values. Generally, supplementation of vitamin E narrowed the gaps between treatment and control results.

\section{Biochemical Analyses}

Data of the measured biochemical parameters are presented in Table 2. Generally, there were insignificant differences between control and vitamin $E$ treatments. The serum activity of AST in control mice was found to be 69.00,70.00, and $70.66 \mathrm{U} / \mathrm{L}$, respectively, in dams, female pups, and male pups. The mixture treatment caused significant elevation ( $p \leq 0.0 \mathrm{l}$ ), and coadministration of vitamin $E$ with the pesticide mixture lead to some improvement. In the meantime, the enzyme activity in female and male pups approached the control values without significant differences. A significant elevation $(p \leq 0.01)$ in serum activity of ALT was obtained for the mixture treatments (70.00, 67.00, and $62.33 \mathrm{U} / \mathrm{L}$ ) compared with that for the control treatments (30.00, 31.00, and 31.66 U/L), respectively, for dams, female pups, and male pups. The mixture+vitamin E treatments recorded values

Table I. Body, absolute, and relative organ weights of mouse dams and their pups treated with the mixture, with and without vitamin E supplementation, during lactation periods

\begin{tabular}{|c|c|c|c|c|c|c|c|c|c|c|c|}
\hline \multirow[b]{2}{*}{ Treatment } & \multicolumn{5}{|c|}{ Organs Weights (g) } & \multirow[b]{2}{*}{ Ovary/Testis } & \multicolumn{5}{|c|}{ Relative Organs Weights (\%) } \\
\hline & B.Wt. (g) & Liver & Kidney & Heart & Spleen & & Liver & Kidney & Heart & Spleen & Ovary/Testis \\
\hline$\overline{C D}$ & $28.26 \pm 0.97$ & $2.23 \pm 0.23$ & $0.41 \pm 0.01$ & $0.23 \pm 0.02$ & $0.09 \pm 0.01$ & $0.02 \pm 0.01$ & $8.12 \pm 0.85$ & $1.44 \pm 0.06$ & $0.82 \pm 0.06$ & $0.32 \pm 0.01$ & $0.06 \pm 0.01$ \\
\hline$\vee D$ & $27.50 \pm 1.74$ & $2.34 \pm 0.40$ & $0.43 \pm 0.53$ & $0.25 \pm 0.06$ & $0.15 \pm 0.04$ & $0.06 \pm 0.04$ & $8.49 \pm 1.20$ & $1.55 \pm 0.10$ & $0.89 \pm 0.12$ & $0.34 \pm 0.13$ & $0.08 \pm 0.03$ \\
\hline MD & $27.23 \pm 0.63$ & $2.20 \pm 0.46$ & $0.43 \pm 0.01$ & $0.22 \pm 0.02$ & $0.29 \pm 0.03^{* *}$ & $0.02 \pm 0.01$ & $8.09 \pm 0.35$ & $1.58 \pm 0.02$ & $0.79 \pm 0.02$ & $0.89 \pm 0.04^{* *}$ & $0.06 \pm 0.01$ \\
\hline$(M D+V)$ & $28.30 \pm 0.44$ & $2.56 \pm 0.28$ & $0.41 \pm 0.01$ & $0.24 \pm 0.03$ & $0.08 \pm 0.01$ & $0.03 \pm 0.01$ & $9.04 \pm 0.07$ & $1.45 \pm 0.05$ & $0.84 \pm 0.05$ & $0.28 \pm 0.01$ & $0.09 \pm 0.04$ \\
\hline $\mathrm{CP}($ q) & $7.88 \pm 0.68$ & $0.42 \pm 0.31$ & $0.12 \pm 0.01$ & $0.07 \pm 0.01$ & $0.05 \pm 0.01$ & $0.07 \pm 0.02$ & $5.28 \pm 0.31$ & $1.49 \pm 0.07$ & $0.86 \pm 0.05$ & $0.58 \pm 0.04$ & $0.08 \pm 0.02$ \\
\hline$V P(q)$ & $8.16 \pm 0.25$ & $0.41 \pm 0.11$ & $0.12 \pm 0.01$ & $0.06 \pm 0.02$ & $0.04 \pm 0.01$ & $0.08 \pm 0.01$ & $5.19 \pm 0.28$ & $1.52 \pm 0.04$ & $0.76 \pm 0.01$ & $0.54 \pm 0.04$ & $0.10 \pm 0.02$ \\
\hline$M P(q)$ & $7.54 \pm 0.20$ & $0.51 \pm 0.04^{*}$ & $0.12 \pm 0.03$ & $0.05 \pm 0.01$ & $0.03 \pm 0.01$ & $0.06 \pm 0.01$ & $6.82 \pm 0.30 *$ & $1.54 \pm 0.03$ & $0.70 \pm 0.02^{*}$ & $0.37 \pm 0.04^{*}$ & $0.08 \pm 0.01$ \\
\hline$(M P+V)(q)$ & $6.86 \pm 0.34$ & $0.41 \pm 0.03$ & $0.10 \pm 0.01$ & $0.05 \pm 0.01$ & $0.03 \pm 0.01$ & $0.06 \pm 0.01$ & $5.99 \pm 0.14$ & $1.47 \pm 0.02$ & $0.73 \pm 0.02$ & $0.42 \pm 0.03$ & $0.09 \pm 0.02$ \\
\hline $\mathrm{CP}\left(0^{x}\right)$ & $7.00 \pm 0.58$ & $0.42 \pm 0.031$ & $0.10 \pm 0.11$ & $0.06 \pm 0.01$ & $0.04 \pm 0.01$ & $0.04 \pm 0.01$ & $5.94 \pm 0.16$ & $1.43 \pm 0.06$ & $0.83 \pm 0.06$ & $0.56 \pm 0.08$ & $0.57 \pm 0.07$ \\
\hline$\vee P\left(0^{x}\right)$ & $8.30 \pm 0.42$ & $0.40 \pm 0.11$ & $0.12 \pm 0.01$ & $0.05 \pm 0.01$ & $0.05 \pm 0.01$ & $0.04 \pm 0.01$ & $6.08 \pm 0.37$ & $1.49 \pm 0.10$ & $0.77 \pm 0.03$ & $0.59 \pm 0.05$ & $0.46 \pm 0.06$ \\
\hline$M P\left(0^{x}\right)$ & $7.14 \pm 0.93$ & $0.51 \pm 0.04^{*}$ & $0.11 \pm 0.04$ & $0.05 \pm 0.02$ & $0.03 \pm 0.01$ & $0.03 \pm 0.01$ & $7.20 \pm 0.21^{*}$ & $1.53 \pm 0.04$ & $0.71 \pm 0.03 *$ & $0.46 \pm 0.04^{*}$ & $0.46 \pm 0.01$ \\
\hline$(M P+V)\left(\sigma^{x}\right)$ & $6.96 \pm 0.52$ & $0.41 \pm 0.03$ & $0.10 \pm 0.01$ & $0.05 \pm 0.01$ & $0.03 \pm 0.01$ & $0.05 \pm 0.02$ & $5.91 \pm 0.62$ & $1.42 \pm 0.02$ & $0.75 \pm 0.05$ & $0.49 \pm 0.04$ & $0.53 \pm 0.02$ \\
\hline
\end{tabular}

Mixture: Atrazine+Chlorpyrifos+Endosulfan
Symbols Abbreviation: $C=$ control; $V=$ vitamin $E ; M=$ mixture; $D=$ dams; $P=$ pups

Statistical: - Insignificant; ${ }^{*}=$ Significant $(P<0.05) ; * *$ Highly Significant $(P<0.01)$; Mothers $(n=3)$; o Pups ( $\left.=5\right)$; or $^{*}$ ups ( $\left.n=5\right)$

Relative Weight=Organ Weight/Body Weight*100 
Table 2. Activities and/or concentration levels of biochemical parameters in serum/tissue of mouse dams and their pups following exposure during lactation to a mixture of pesticides, with and without vitamin E supplementation

\begin{tabular}{|c|c|c|c|c|c|c|c|c|c|c|c|c|}
\hline \multirow[b]{3}{*}{ Treatment } & \multicolumn{12}{|c|}{ Liver and Kidney Functions } \\
\hline & \multicolumn{3}{|c|}{$\mathrm{AST}(\mathrm{U} / \mathrm{L})$} & \multicolumn{3}{|c|}{$A L T(U / L)$} & \multicolumn{3}{|c|}{$\operatorname{ALP}(U / L)$} & \multicolumn{3}{|c|}{ Urea $(\mathrm{mg} / \mathrm{dL})$} \\
\hline & Dams & Female & Male & Dams & Female & Male & Dams & Female & Male & Dams & Female & Male \\
\hline VE & $68.33 \pm 2.40$ & $70.00 \pm 1.15$ & $69.33 \pm 1.85$ & $29.33 \pm 1.76$ & $31.33 \pm 1.76$ & $30.66 \pm 1.20$ & $69.00 \pm 2.08$ & $55.00 \pm 2.51$ & $55.66 \pm 2.33$ & $42.66 \pm 1.20$ & $35.66 \pm 0.88$ & $35.66 \pm 1.85$ \\
\hline Mix & $110.66 \pm 0.88^{* *}$ & $94.66 \pm 1.76^{*}$ & $95.00 \pm 1.52 *$ & $70.00 \pm\left. 2.5\right|^{* *}$ & $67.00 \pm 1.52^{* *}$ & $62.33 \pm 1.45^{* *}$ & $145.00 \pm 5.50^{* *}$ & $111.00 \pm 2.08^{* *}$ & $\| 0.33 \pm 2.60^{* *}$ & $61.00 \pm 2.08^{*}$ & $45.33 \pm 1.85^{*}$ & $48.66 \pm 0.88^{*}$ \\
\hline$M i x+V E$ & $81.33 \pm 4.09 *$ & $71.33 \pm 3.48$ & $72.33 \pm 1.45$ & $37.66 \pm 2.96$ & $36.00 \pm 2.08$ & $32.66 \pm 1.20$ & $97.66 \pm 1.45^{*}$ & $69.33 \pm 1.45^{*}$ & $66.33 \pm 1.20^{*}$ & $43.66 \pm 2.33$ & $37.33 \pm 1.76$ & $38.00 \pm 1.15$ \\
\hline
\end{tabular}

\begin{tabular}{|c|c|c|c|c|c|c|c|c|c|c|c|c|}
\hline \multirow[b]{3}{*}{ Treatment } & \multicolumn{12}{|c|}{ Cholinesterase and Antioxidant Enzymes } \\
\hline & \multicolumn{3}{|c|}{ BuChE $(U / L)$ in sera } & \multicolumn{3}{|c|}{ MDA (nmol/g tissue) } & \multicolumn{3}{|c|}{$\mathrm{SOD}(\mathrm{U} / \mathrm{g}$ tissue $)$} & \multicolumn{3}{|c|}{ Catalase $(\mu \mathrm{mol} / \mathrm{min} / \mathrm{mL})$ in sera } \\
\hline & Dams & Female & Male & Dams & Female & Male & Dams & Female & Male & Dams & Female & Male \\
\hline Control & $3378.66 \pm 22.51$ & $1544.33 \pm 25.12$ & $1487.33 \pm 8.96$ & $81.33 \pm 3.52$ & $51.00 \pm 1.52$ & $53.00 \pm 2.51$ & $210.66 \pm 1.45$ & $190.33 \pm 2.96$ & $190.66 \pm 4.97$ & $397.66 \pm 5.36$ & $384.66 \pm 4.66$ & $392.00 \pm 2.08$ \\
\hline VE & $3351.33 \pm 25.72$ & $1535.66 \pm 33.54$ & $1438.66 \pm 13.86$ & $79.33 \pm 5.04$ & $52.00 \pm 3.46$ & $51.33 \pm 3.52$ & $209.00 \pm 7.37$ & $192.00 \pm 5.29$ & $190.00 \pm 7.00$ & $400.00 \pm 5.77$ & $389.66 \pm 4.33$ & $394.33 \pm 3.48$ \\
\hline Mix & $3155.00 \pm 8.66^{* *}$ & * $1243.33 \pm 23.33 *$ & $* 280.00 \pm 26.45 * *$ & $117.33 \pm 1.45^{* *}$ & $64.66 \pm 0.88^{*}$ & $67.33 \pm 1.33^{*}$ & $163.33 \pm 2.02^{* *}$ & $158.66 \pm 3.52^{* *}$ & $156.66 \pm 2.40^{* *}$ & $236.00 \pm 3.05^{* *}$ & $228.33 \pm 2.60^{* *}$ & $227.66 \pm 1.45^{* *}$ \\
\hline$M i x+V E$ & $3253.33 \pm 20.27^{*}$ & * $1362.00 \pm 16.65^{*}$ & $1360.33 \pm 7.26^{*}$ & $69.33 \pm 2.33^{*}$ & $53.33 \pm 1.20$ & $53.33 \pm 2.40$ & $188.33 \pm 4.40^{*}$ & $172.66 \pm 2.60^{*}$ & $174.33 \pm 2.96^{*}$ & $340.66 \pm 2.33^{*}$ & $330.00 \pm 2.88^{*}$ & $335.00 \pm 2.88^{*}$ \\
\hline
\end{tabular}

Pesticide mixture (Mix): Atrazin+Chlorpyrifos+Endosulfan. VE: vitamin E

Statistical: compared with control value in the same column: * means significant difference at $p \leq 0.05$; ** means high significant difference at $p \leq 0.01$. $n=3$.

insignificantly different compared with control treatments. The pesticide mixture treatments caused high elevation $(p \leq 0.01)$ in the ALP activity (145.00, III.00, and II0.33 U/L) compared with the control treatments $(73.33,54.33$, and $54.66 \mathrm{U} / \mathrm{L})$, respectively, for dams, female pups and male pups. Coadministration of vitamin E with the mixture improved the ALP activities to some extent. A similar trend was obtained for urea concentrations (Table 2).

The serum activity of BuChE in control mice was found to be 3378.66, 1544.33, and $1487.33 \mathrm{U} / \mathrm{L}$, respectively, in dams, female pups, and male pups (Table 2). The mixture treatment caused significant decline $(p \leq 0.01)$. Coadministration of vitamin $E$ with the pesticide mixture improved the enzyme activity to some extent. A high significant elevation $(p \leq 0.01)$ in the activity of lipid peroxidation (LPO) in terms of MDA was obtained for the mixture treatment in mouse dams (II7.33nmol/g tissue), while significant elevation ( $p \leq 0.05$ ) was recorded in female and male pups (64.66 and $67.33 \mathrm{nmol} / \mathrm{g}$ tissue, respectively) compared with the respective control values. The activity of SOD in control mice was found to be 210.66, 190.33, and 190.66 U/g tissues, respectively, in dams, female pups, and male pups. These values were significantly decreased $(p \leq 0.01)$ in the mice treated with the pesticide mixture. Coadministration of vitamin $E$ with the pesticide mixture improved the enzyme activity to some extent. A nearly similar trend was obtained for the serum catalase (CAT) activity (Table 2).

\section{Histopathology Examination}

Microscopic examination of sections from the liver, kidneys, ovaries, and testes obtained from the animals subjected to different treatments in the present study was performed. Figure I illustrates the histopathological structure of the studied sections obtained from the normal (control) groups. The control latter was considered as a base for comparing the histopathological alterations in the pesticide mixture groups with and without vitamin E supplementation. Sections of control organs (Figure I) were characterized by a normal histopathological structure of the hepatic lobules, central veins, and hepatocytes. Renal parenchyma and tubules were characteristic of anormal histopathological struc- ture of the kidneys. Graffian follicle and corpus luteum were characteristic of a normal ovary. Sections of the testes were characterized by normal seminiferous tubules, and those of the ovaries were characterized by a normal corpus luteum (Figure la-i).

Based on a study by Brunt et al. (18), such alterations were adopted and scored in terms of degree of cell damage as follows:

$(0)=$ no change, $(1)=$ mild change (e.g., $<25 \%$ cell damage), (2) $=$ moderate change (e.g., 25\%-50\% cell damage), and (3)=severe change (e.g., $>50 \%$ cell damage).

The results of histological alterations in the mixture alone and in conjunction with vitamin $E$ treatments could be depicted from the data presented in Table 3.

\section{DISCUSSION}

Pregnant and lactating women are considered as a special risk group due to the possibility of an increased risk of acute lymphocytic leukemia to their children/fetus if these women use pesticides during these critical stages even when the babies are in the mother's womb (19). A fetus is more vulnerable to the toxic effects of environmental exposure than children or adults (20). There are many factors involved in the transfer of chemicals into the breast milk and subsequently to the suckling neonate. The quantity of pesticides that is passed to the infant via the breast milk is influenced by many variables, including age, the chemical in concern, the level/duration of exposure, and the developmental period during which the exposure occurs (2l).

To the best of our knowledge, there are no studies on the ACE mixture tested here with respect to hepatorenal dysfunction and oxidative stress that may occur in pregnant and/or lactating animals and on protective effects of antioxidants, such as vitamin $E$. Only in in vitro studies, the effect of the concerned mixture was evaluated on the liver cell defense system using human and mice cultured hepatocytes (3). However, studies were previously conducted on individual compounds with special focus pertaining to 


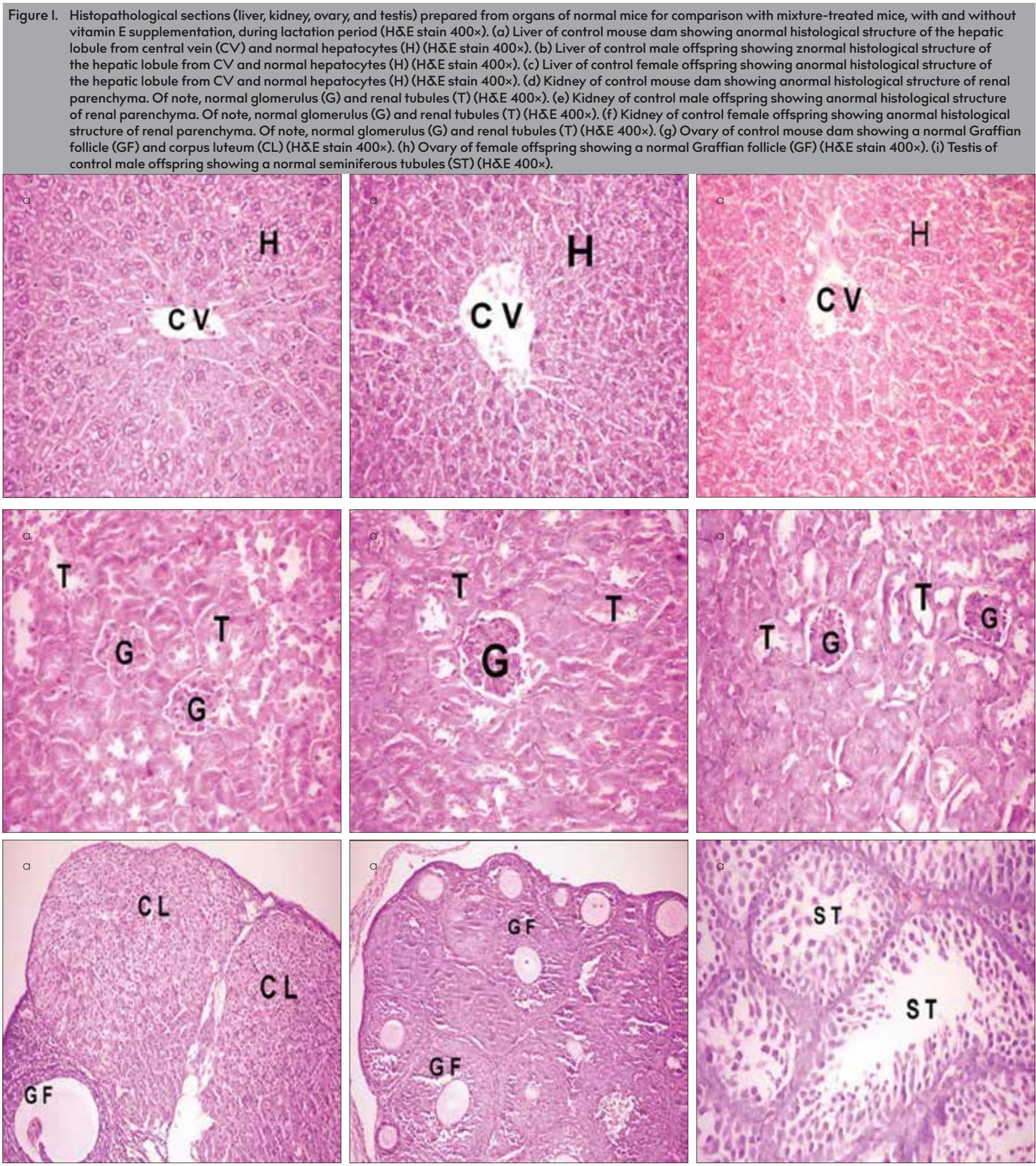

their adverse effects during gestation and lactation and on the ameliorative effects of antioxidants such as vitamin E (5-7).

In toxicological studies, evaluation of organ toxicity is an important criterion. Generally, increase or decrease of organ weights than normal may be considered as a sign of toxicity. The results of the present study revealed that there were insignificant changes in the body weight with all treatments (Table I). On the other hand, the significant increase in the relative liver weight, particularly in suckling pups, may be attributed to the induction of hepatomegaly, which was designated as an important reason for losing of body weight (22). Fortunately, the ACE treatments did not cause significant changes in the relative weights of the kidneys, ovaries, and testes in experimental mice (Table I). Vi- 
Table 3. Histopathologic changes based on scoring severity of injury in different organs from mouse dams and their pups following exposure to pesticide mixture, with and without vitamin E supplementation, during lactation

\begin{tabular}{|c|c|c|c|c|c|c|}
\hline & & Mixture & & Mixture+vitamin E & & \\
\hline Histopathological changes & Dams & Pups (F) & Pups (M) & Dams & Pups (F) & Pups (M) \\
\hline \multicolumn{7}{|l|}{ Liver } \\
\hline - Vacuolar degeneration of hepatocytes & 3 & 2 & 2 & 0 & 0 & 0 \\
\hline -Cytoplasmic vacuolization of hepatocytes & 3 & 2 & 2 & । & 0 & । \\
\hline -Congestion & 2 & 0 & 0 & 0 & 0 & 0 \\
\hline -Kupffer cell activation & 0 & 0 & 0 & 0 & 0 & 0 \\
\hline -Pyknosis of nuclei & 3 & 0 & 0 & 0 & 0 & 0 \\
\hline \multicolumn{7}{|l|}{ Kidney } \\
\hline -Vacuolation of glomerular tuft & 2 & 0 & 0 & 1 & 0 & 0 \\
\hline - Vacuolation of epithelial lining renal tubules & 3 & 3 & 3 & 2 & 2 & 0 \\
\hline -Focal renal hemorrhage & 3 & 0 & 3 & 0 & 0 & 0 \\
\hline \multicolumn{7}{|l|}{ Ovary } \\
\hline -Atretic follicles & 2 & 2 & - & 0 & 0 & - \\
\hline -Vacuolated corpus luteum & 2 & 2 & - & 1 & 0 & - \\
\hline -Hyperplasia of interstitial cells & 2 & 0 & - & 0 & 0 & - \\
\hline -Follicles of different stages of development & 2 & 0 & & 0 & 0 & - \\
\hline \multicolumn{7}{|l|}{ Testis } \\
\hline $\begin{array}{l}\text {-Degeneration of spermatogoneal } \\
\text { cells lining seminiferous tubules }\end{array}$ & - & - & 3 & - & - & । \\
\hline -Necrosis of germ cells & - & - & 3 & - & - & 0 \\
\hline -Intertubular edema & - & - & 3 & - & - & 0 \\
\hline -Atrophy of seminiferous tubules & - & - & 3 & - & - & 0 \\
\hline
\end{tabular}

tamin E supplementation to ACE treatments showed that body and organ weight values insignificantly differed compared with the corresponding control values. These results may refer to the tested low dose of the ACE mixture and coincide with the effect of vitamin $E$ on $A(5), E(6)$, and $C(7)$ when tested individually at $A D I$ values against pregnant and lactating mice.

The release of intracellular enzymes (e.g., AST, ALT, and ALP) in the circulation following exposure to pesticides is one of the most sensitive indicators of hepatocyte injury. The elevated activity of these enzymes, as observed here, is indicative of cellular leakage and loss of functional integrity of the liver cell membranes (23). The release of extra amounts of ALT and ALP (up to 3 and 2 times, respectively, of their upper normal limits; ULN) may be indicative of severe liver injury due to ACE treatments (Table 2) (24).

Kidney is one of the target organs attacked by acute and chronic exposure to pesticides (25). Elevation of urea concentrations in serum of treated rats (Tables 2) may be indicative of kidney dysfunction as a result of oxidative damage (II).

Cholinesterase (ChE) or pseudocholinesterase is synthesized mainly in the hepatocytes and secreted into the blood stream. In liver dysfunction, its activity is declined due to reduced synthesis in contrast to other serum enzymes involved in liver function whose activities increase as a result of increased release from their cellular sources following cell membrane damage (26). In this respect, changes in ChE activity reflect diminished synthetic capacity of the hepatic parenchyma (27). In the present study, the decline of BuChE seemed to occur in a manner resembling that previously reported for individual compounds of the tested ACE mixture (5-7). Following subchronic and chronic exposure to OP pesticides, a correlation between AChE inhibition and LPO levels in erythrocytes was found (28).
In fact, the toxicity of biologically active substances (e.g., pesticides) is associated with the formation of ROS. These ROS are responsible of inducing oxidative stress in the tissues and chronic permanent damage (II). The harmful effects of ROS are balanced by the antioxidant action of nonenzymatic and enzymatic antioxidants, which are molecules containing an unshared electron (I3). It is well documented that many pesticides may induce oxidative stress following acute exposure in humans and animals $(13,29,30)$. Increased LPO in various tissues may be one of the molecular mechanisms involved in pesticide-induced toxicity (13). LPO is a marker of oxidative damage caused by many substances, including pesticides. MDA is a stable end product of LPO; therefore, it can be used as an indirect measure of the cumulative LPO. SOD provides the first line of defense against oxygen-derived free radicals and decreases oxidative stress by dismutation $\mathrm{O}_{2}^{-}$(31). Elevation of MDA and decline of SOD activities by the ACE mixture could be attributed to the oxidative stress-related effects of the tested mixture. A diet containing low doses of POP mixture (e.g., E, C, naphthalene, and benzopyrane) was reported to induce oxidative stress in brain cytosol and mitochondria; these results may support our findings (32).

Several substances, including vitamin $E$, were used to alleviate the toxic effects of pesticide-induced oxidative stress in experimental animals. Antioxidants, such as vitamin E, are important biological free-radical scavengers in cell membranes and protect cells from the damaging effects of free radicals $(13,33)$. Interestingly, the vitamin showed its ability to ameliorate the oxidative stress induced by the ACE mixture (Table 2). To the best of our knowledge, such studies on the ACE mixture tested here may be not investigated before. Only green tea polyphenols (as an example for natural polyphenols) or butylated hydroxytolvene (as an example for artificial polyphenols) were found to 


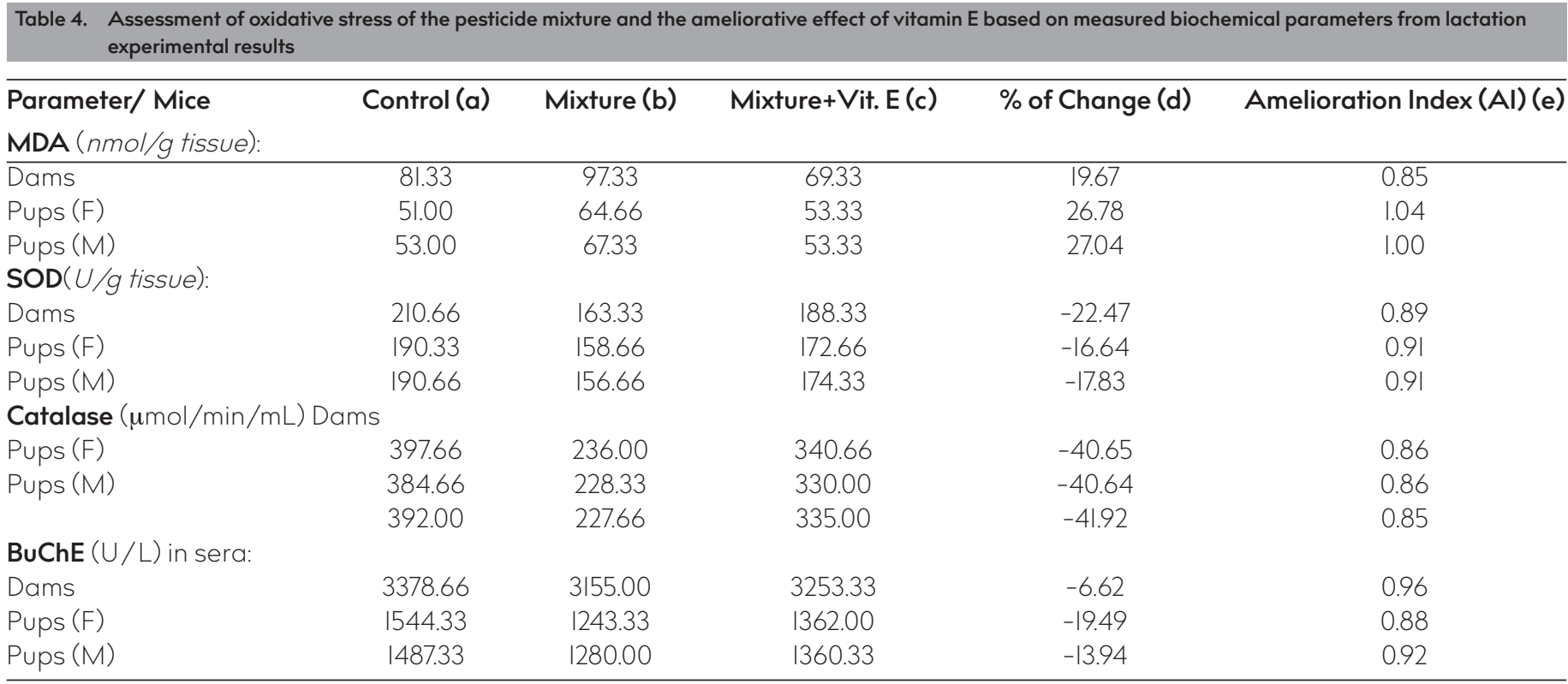

Data refer to Table 2

dPercent of change $=(b-a) / a \times 100$

eAmeliorative Index $(\mathrm{Al})=\mathrm{c} / \mathrm{a}$

attenuate toxicity of a mixture ( $C$, fenitrothion, and lambda cyhalothrin) against male rats (12).

The hepatic and renal dysfunction results (Table 2) corroborated the histopathological lesions observed in the present study (Table 3). Also, the results revealed the protective effect of vitamin E against ACE-induced histopathological impairments in the liver, kidneys, ovaries, and testes of the experimental mice.

The pattern of biochemical alterations induced by the ACE mixture in the present investigation (Table 2 ) resembled those previously reported to be induced by individual pesticides (5-7). In other words, aminotransferases (AST and ALT), ALP, and MDA were elevated and BuChE and SOD were declined, both for individual pesticides and the ACE mixture, in nearly equal valves. Supporting our findings, a previous study by de Castro and Chiorato (34) reported that the effect of combined exposure to methamidophos and chlorothalonil on the development of suckling rats was not found to have a greater toxic effect than that of exposure to only one of the two insecticides.

Based on a study by Mansour and Gamet-Pyrastre (7), it was possible to assess the effect of the ACE mixture on the liver and kidney biomarkers as well as on AOEs in a "quantitative manner" by: a) calculating the percentage of change in ACE-treated groups relative to that in control untreated groups, and b) estimating the "amelioration Index (AI)" by comparing the results of AOEs (e.g., MDA, SOD, and CAT) in ACE mixture+Vit. E groups with the results of control groups to assess the ameliorative effect of the vitamin. As Al was approaching "I," the amelioration reached a high degree of normalization with respect to the control value.

According to the data presented in Table 4, the change in MDA activity accounted to $19.67 \%, 26.78 \%$, and $27.04 \%$, respectively, in dams, female pups, and male pups. In other words, the estimated values reflect how much deviation than normal occurred in MDA activity due to exposure to the mixture. Changes in MDA activity in the mice dams were generally less than those in the pups.

Changes in SOD, CAT, and BuChE activities, both in mouse dams and their pups, can be easily depicted from the results given in Table 4. Generally, dams seemed to be more vulnerable to alterations in the abovementioned biochemical parameters than their offspring.

The efficiency of vitamin E to alleviate the oxidative stress of the ACE mixture is expressed in terms of "Al" (Table 4). The Al of vit. E for MDA was0.85, 1.04, and 1.00, respectively, for dams, female pups, and male pups. The Al of vit. E for SOD, CAT, and BuChE ranged between 0.85 and 0.96 . Values of $\mathrm{Al}$ approaching $1.0 \mathrm{in}-$ dicated high improvement of the biochemical parameters due to coadministration of vitamin E. The present results are supported by our previously published investigations on individual pesticides of the tested ACE mixture (5-7) and revealed the ability of vitamin $E$ to ameliorate the toxic effects caused by this mixture.

\section{CONCLUSION}

This study indicates that the ACE mixture containing A, C, and E, each at a dose equivalent to its respective $A D I$ value, was able to induce hepatorenal dysfunction and oxidative stress in lactating mice and their suckling pups, which were not directly treated with the mixture. The pups were more affected than the dams with respect to alterations in MDA and BuChE activities, whereas the opposite was observed with respect to SOD activities. Coadministration of vitamin $\mathrm{E}$ with the ACE mixture resulted in pronounced ameliorative effects in all the tested animals. The overall findings may reveal the ability of the ACE mixture to exert its toxic effects through breastfeeding; however, such adverse effects could be alleviated to a great extent by vitamin E supplementation. The findings of this study may support the need to further investigate the adverse effects of exposure to low doses of commonly used pes- 
ticides and the reproductive effects on newborns. Also, the search for powerful antioxidants should be given special attention.

Ethics Committee Approval: Ethics committee approval was received for this study from the Ethical Committee on animal testing in TOXALIM Research Centre in Food Toxicology, Toulouse, France.

Peer-review: Externally peer-reviewed.

Author contributions: Concept - S.A.M., L.G.P.; Design - S.A.M., L.G.P.; Supervision - S.A.M., L.G.P.; Resource - S.A.M., L.G.P.; Materials - S.A.M., L.G.P., M.F.G.; Data Collection and/or Processing - S.A.M., L.G.P., M.F.G., K.A.M.; Analysis and /or Interpretation - S.A.M., M.F.G.; Literature Search - S.A.M., L.G.P., M.I.A.; Writing -S.A.M., M.F.G.; Critical Reviews -S.A.M., M.I. A., K.A.M.

Conflict of Interest: No conflict of interest was declared by the authors.

Financial Disclosure: The authors declared that this study has received no financial support.

\section{REFERENCES}

I. Anderson HA, Wolff MS. Environmental contaminations in human milk. J Expo Anal Environ Epidemiol 2000; 10:755-760. [CrossRef]

2. Nawaz A, Razpotnik A, Rouimi P, de Sousa G, Cravedi JP, Rahmani R. Cellular impact of combinations of endosulfan, atrazine, and chlorpyrifos on human primary hepatocytes and HepaRG cells after short and chronic exposures. Cell Biol Toxicol 2014; 30:17-29. [CrossRef]

3. Rouimi P, Zucchini-Pascal N, Dupont G, et al. Impacts of low doses of pesticide mixtures on liver cell defence systems. Toxicol Vitro 2012; 26:718-726. [CrossRef]

4. ATSDR. Toxicological Profile for Endosulfan. Agency for Toxic Substances and Disease Registry, Division of Toxicology and Human Health Sciences/Environmental Toxicology Branch, 1600 Clifton Road, NE Mailstop F-57 Atlanta, Georgia 30329-4027; 2015.

5. Mansour SA, Gamet-Payrastre L, Mohamed DA, Gad MF. Ameliorative effect of vitamin E to mice dams and their pups following exposure of mothers to atrazine during gestation and lactation periods. Science Jet 2013; 32:3.

6. Mansour SA, Mohamed DA, Gamet-Payrastre L. Indirect exposure of mice pups to endosulfan via their dams during gestation and lactation periods and the ameliorative effect of vitamin E. Hum Exper Toxicol 2014; 33:911-927. [CrossRef]

7. Mansour SA, Gamet-Payrastre L. Ameliorative effect of vitamin E to mouse dams and their pups following exposure of mothers to chlorpyrifos during gestation and lactation periods. Toxicol Industr Health 2016; 32: I179-II96. [CrossRef]

8. Carpenter DO, Arcaro K, Spink DC. Understanding the human health effects of chemical mixtures. Environ Health Perspec 2002; II0: 25-42. [CrossRef]

9. Belden JB, Lydy MJ. Impact of atrazine on organophosphate insecticide toxicity. Environ Toxicol Chem 2000; 19:2266-2274. [CrossRef]

10. DeLorenzo ME, Lorimar S. Individual and mixture toxicity of three pesticides; atrazine, chlorpyrifos, and chlorothalonil to the marine phytoplankton species Dunaliella tertiolecta. J Environ Sci Health B 2003; 5:529-538. [CrossRef]

II. Abdollahi M, Mostafalou S, Pournourmohammadi S, Shadnia S. Oxidative stress and cholinesterase inhibition in saliva and plasma of rats following sub chronic exposure to malathion. Comp Biochem Physiol C: Toxicol Pharmacol 2004; 137:29-34.

12. Gawish A, Elhalwagy MEA. Which can attenuate hepatotoxicity induced by pesticides mixture natural or synthetic phenolic antioxidant. Nat Sci 2009; 5:29-44.

13. Verhagen H, Buijsse B, Jansen E, Bueno-de-Mesquita B. The state of antioxidant affairs. Nutr Today 2006; 41:244-250. [CrossRef]
14. Merhi M, Demur C, Racaud-Sultan C, et al. Gender-linked haematopoietic and metabolic disturbances induced by a pesticide mixture administered at low dose to mice. Toxicology 2010; 267:80-90. [CrossRef]

15. FAO/WHO. Pesticide Residues in Food 20l0. Report of the Joint Meeting of the FAO Panel of Experts on Pesticide Residues in Food and the Environment and the WHO Core Assessment Group on Pesticide Residues, Rome, Italy; September 2010.

16. Kalender S, Kalender Y, Ogutcu A, Uzunhisarcikli M, Durak D, Açikgoz F. Endosulfan-induced cardiotoxicity and free radical metabolism in rats: the protective effect of vitamin E. Toxicology 2004; 202:227-235. [CrossRef]

17. Fishbeck KL, Rasmussen KM. Effect of repeated cycles on maternal nutritional status, lactational performance and litter growth in ad libitum fed and chronically food. J Nutr 1987; |17:1967-1975.

18. Brunt EM, Janney CG, Di Bisceglie AM, Neuschwander-Tetri BA, Bacon BR. Nonalcoholic steatohepatitis: a proposal for grading and staging the histological lesions. Am J Gastroenterol 1999; 94:24672474. [CrossRef]

19. Infante-Rivard C, Labuda D, Krajinovic M, Sinnett D. Risk of childhood leukemia associated with exposure to pesticides and with gene polymorphisms [comment]. Epidemiology 1999; 10:481-487. [CrossRef]

20. Perera FP, IIIman SM, Kinney PL, et al. The challenge of preventing environmentally related disease in young children: community-based research in New York City. Environ Health Perspec 2002; II0:197-204. [CrossRef]

21. Scheuplein R, Charnley G, Dourson M. Differential sensitivity of children and adults to chemical toxicity I. Biological basis. Regul Toxicol Pharmacol 2002; 35:429-447. [CrossRef]

22. Kostka G, Kopeć-Szlezak J, Palut D. Early hepatic changes induced in rats by two hepatocarcinogenicorganohalogen pesticides: bromopropylate and DDT. Carcinogenesis 1996; 17:407-412. [CrossRef]

23. Rajesh MG, Latha MS. Preliminary evaluation of the antihepatotoxic activity of Kamilari, a polyherbal formulation. J Ethnopharmacol 2004; 91:99-104. [CrossRef]

24. Xing-Jiu H, Yang-Kyu C, Hyung-Soon I, Oktay Y, Euisik Y, Hak-Sung K. Aspartate Aminotransferase (AST/GOT) and Alanine Aminotransferase (ALT/GPT) detection techniques. Sensors 2006; 6:756782. [CrossRef]

25. Walmsley RN, White GH. A guide to diagnostic clinical chemistry. 3rd ed. London, UK: Blackwell Publication; 1994, 543.

26. Brown SS, Kalow W, Pilz W, Whittaker M, Woronick CL. The plasma cholinesterases: a new perspective. Adv Clin Chem 198I; 22:I-123. [CrossRef]

27. Moss DM, Henderson AR. Tietz Textbook of Clinical Enzymology. In: Burtis CA, Ashwood ER, editors. WB Saunders Co: Philadelphia, PA, USA; 1999; 617-721.

28. Ranjbar A, Pasalar P, Abdollahi M. Induction of oxidative stress and acetylcholinesterase inhibition in organophosphorous pesticide manufacturing workers. Hum Exper Toxicol 2002; 21:179-182. [CrossRef]

29. Mansour SA, Mossa AH. Adverse effects of lactational exposure to chlorpyrifos in suckling rats. Hum Exp Toxicol 2010; 29:77-92. [CrossRef]

30. Mansour SA, Mossa AH. Adverse effects of exposure to low doses of chlorpyrifos in lactating rats. Toxicol Industr Health 20II; 27:213-224. [CrossRef]

31. McCord JM, Fridovich I. Superoxide dismutase: an enzymatic function for erythrocuprein (hemocuprein). J Biol Chem 1969; 244:6049-6055.

32. Lahovel A, Kebieche M, Lakroun Z, et al. Chronic exposure of female rats to a low dose POPs mixture induced oxidative stress in brain cytosol and mitochondria. Int Res J Earth Sci 2015; 3: I-8.

33. Horwitt MK. Vitamin E: a reexamination. Am J Clin Nutr 1976; 29:569-578.

34. de Castro VLS, Chiorato SH. Effects of separate and combined exposure to the pesticides methamidophos and chlorothalonil on the development of suckling rats. Int J Hyg Environ Health 2007; 210:169-176. [CrossRef] 